\title{
Correction to: Wide genetic diversity in Old World honey bees threaten by introgression
}

\author{
Irene MuÑoz, Pilar De LA RÚA \\ Área de Biología Animal, Dpto. de Zoología y Antropología Física, Facultad de Veterinaria, Universidad de Murcia, \\ Campus de Espinardo, 30100, Murcia, Spain
}

Received 23 March 2021 - Accepted 25 March 2021

Correction to: Apidologie (2021) 52:200-217

https://doi.org/10.1007/s13592-020-00810-0

The article was published with Fig. 6 appearing twice. The figure provided in this corrigendum corresponds to Fig. 5, which is missing from the original but is now provided here:

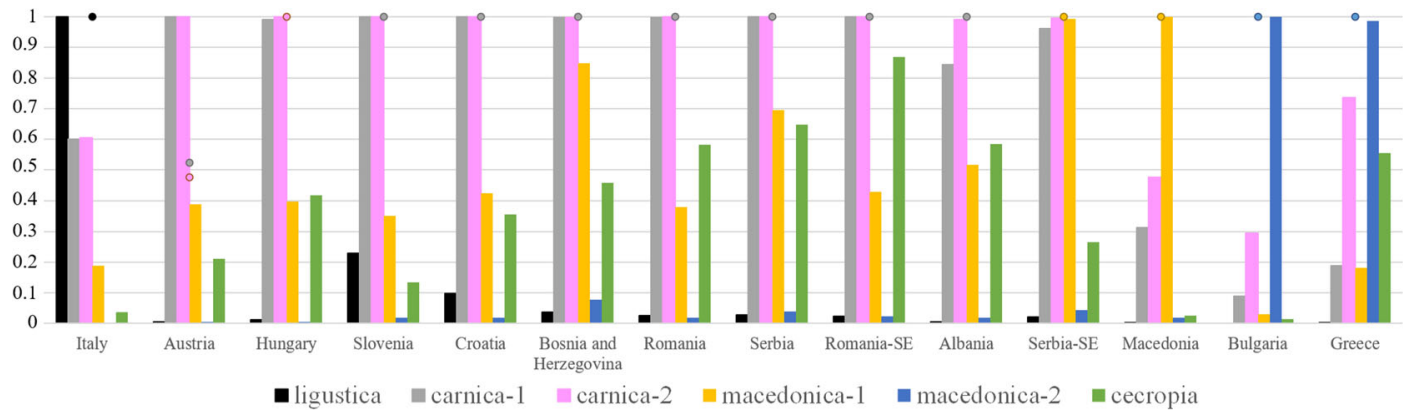

This correction stands to correct the original article.
Publisher's note Springer Nature remains neutral with regard to jurisdictional claims in published maps and institutional affiliations.

Corresponding author: P. De la Rúa, pdelarua@um.es Manuscript editor: Maria Meixner

The online version of the original article can be found at https://doi.org/10.1007/s13592-020-00810-0 